Article

\title{
Low Protein Intakes and Poor Diet Quality Associate with Functional Limitations in US Adults with Diabetes: A 2005-2016 NHANES Analysis
}

\author{
Stephanie M. Fanelli ${ }^{1}$, Owen J. Kelly ${ }^{2}$, Jessica L. Krok-Schoen ${ }^{3}$ and Christopher A. Taylor ${ }^{1, *(D)}$ \\ 1 Medical Dietetics, The Ohio State University, Columbus, OH 43210, USA; fanelli.18@buckeyemail.osu.edu \\ 2 Department of Molecular and Cellular Biology, Sam Houston State University, Conroe, TX 77304, USA; \\ ojk003@shsu.edu \\ 3 School of Health and Rehabilitation Sciences, The Ohio State University, Columbus, OH 43210, USA; \\ jessica.schoen@osumc.edu \\ * Correspondence: taylor.1043@osu.edu; Tel.: +1-614-688-7972
}

Citation: Fanelli, S.M.; Kelly, O.J.; Krok-Schoen, J.L.; Taylor, C.A. Low Protein Intakes and Poor Diet Quality Associate with Functional Limitations in US Adults with Diabetes: A 2005-2016 NHANES Analysis. Nutrients 2021, 13, 2582. https:// doi.org/10.3390/nu13082582

Academic Editor: Luigi Palla

Received: 3 June 2021

Accepted: 24 July 2021

Published: 27 July 2021

Publisher's Note: MDPI stays neutral with regard to jurisdictional claims in published maps and institutional affiliations.

Copyright: (c) 2021 by the authors Licensee MDPI, Basel, Switzerland. This article is an open access article distributed under the terms and conditions of the Creative Commons Attribution (CC BY) license (https:/ / creativecommons.org/licenses/by/ $4.0 /)$.

\begin{abstract}
Type 2 diabetes is associated with an increased risk for sarcopenia. Moreover, sarcopenia correlates with increased risk for falls, fractures, and mortality. This study aimed to explore relationships among nutrient intakes, diet quality, and functional limitations in a sample of adults across levels of glycemic control. Data were examined from 23,487 non-institutionalized adults, 31 years and older, from the 2005-2016 National Health and Nutrition Examination Survey. Hemoglobin A1c (\%) was used to classify level of glycemic control: non-diabetes $(<5.7 \%)$; pre-diabetes $(5.7-6.4 \%)$; diabetes $(\geq 6.5 \%)$. Dietary data were collected from a single 24 -h dietary recall. Participants were categorized as meeting or below the protein recommendation of $0.8 \mathrm{~g} / \mathrm{kg}$ of body weight. Physical functioning was assessed across 19-discrete physical tasks. Adults below the protein recommendation consumed significantly more carbohydrate and had lower diet quality across all glycemic groups compared to those who met the protein recommendation $(p<0.001)$. Adults with diabetes who did not meet protein recommendations had significantly poorer diet quality and significantly higher mean number of functional limitations. A greater percent of adults with diabetes who did not meet the protein recommendation reported being physically limited for most activities, with more than half (52\%) reporting limitations for stooping, crouching, and kneeling. This study underscores the potential for physical limitations associated with low protein intakes, especially in adults with diabetes. In the longer term, low protein intakes may result in increased risk of muscle loss, as protein intake is a critical nutritional factor for prevention of sarcopenia, functional limitations, and falls.
\end{abstract}

Keywords: diabetes; protein; diet quality; dietary patterns; NHANES; sarcopenia; physical limitations

\section{Introduction}

Diet plays a vital role in maintaining health and preventing and managing chronic disease. Type 2 diabetes (diabetes) is a progressive disease affecting more than 30 million adults in the US [1]. Prevalence is expected to increase due to rising rates of obesity, physical inactivity, aging, and urbanization $[2,3]$. In addition to increased morbidity and mortality risk [4], diabetes is associated with sarcopenia, a condition of low muscle mass, function, and quality, further linked to physiological aging [5,6], and impaired physical functioning $[7,8]$. Sarcopenia is associated with increased risk for falls and fractures in individuals with diabetes [9], as well as decreased quality of life and frailty [10]. Hyperglycemia and insulin resistance may be central to the development of sarcopenia in aging and may also be related to time from diabetes diagnosis [11] due to micro- and macrovascular complications [12]. Although age remains the strongest risk factor [13], hyperglycemia and insulin resistance have been shown to be independent risk factors for sarcopenia [7]. 
In addition to physical activity, nutrition interventions, particularly addressing protein intakes, may help prevent and manage sarcopenia [14,15]. The management of sarcopenia is particularly important for older adults as they are at increased risk of falls and fractures. However, research has indicated deficiency in the protein intake of older adults and call for increasing the Recommended Dietary Allowance (RDA) for protein for older adults [16-18]. Additionally, oral medications that are commonly prescribed in mid-life and older adult populations, such as statins, sulfonylureas and glinides, may adversely affect muscle function [19]. Therefore, adequate protein intakes and healthy overall dietary quality [20] are important in the prevention and management of sarcopenia and to maintain functionality. With the evidence lacking for the role of diet and protein intakes in sarcopenia for individuals with diabetes, this study aimed to identify if differences in dietary protein intakes and diet quality are associated with functional limitations in adults with different levels of glycemic control. Examining protein intake and diet quality may provide insight into the relationships between nutrition and functional outcomes in the U.S. population with and without diabetes.

\section{Materials and Methods}

\subsection{Sample Population}

Data were examined from 23,487 non-institutionalized adults aged 31 years and older from the 2005-2016 National Health and Nutrition Examination Survey (NHANES). NHANES is a national nutrition monitoring system that utilized a complex, multistage sampling design to select participants to create a nationally representative sample [21]. Participants with a completed dietary recall interview, measured body weight and glycated hemoglobin data were included in the analyses. To address standard protein recommendations per kilogram of body, women who were pregnant were excluded from the analysis. Demographic and personal data were gathered during in-home interviews, which included gender, race, ethnicity, marital status, education, and income level as a percent of the federal poverty rate. The National Center for Health Statistics Research Ethics Review Board approved all methods carried out in the series of surveys [22].

\subsection{Glycemic Measures}

Glycated hemoglobin (A1c\%) was used to categorize levels of glycemia and indicate the degree of blood glucose control from the prior 90 days. These data were examined from blood collected during the visit to the Mobile Examination Center. A1c data were used to classify sample participants into glycemic groups: nondiabetes (A1c < 5.7\%), prediabetes (A1c 5.7-6.4\%), and diabetes (A1c $\geq 6.5 \%$ ) using criteria from the American Diabetes Association [23].

\subsection{Dietary Intakes and Diet Quality}

Estimates of dietary intake data were assessed from the 24-h dietary recall, which utilized the Automated Multiple Pass Method conducted by trained interviewers in the Mobile Examination Center [24]. This multi-step method allowed for improved accuracy of the intakes of foods and beverages reported as consumed from midnight to midnight of the prior day $[25,26]$. Nutrient and MyPlate intakes were estimated from the Food and Nutrient Database for Dietary Studies as well as the Food Patterns Equivalents Database, respectively, to estimate intakes on the day of record. For a better comparison of nutrient density across varying levels of energy intakes, energy-adjusted nutrient estimations were made represent intakes per 1000 kcals. Meal consumption and skipping were assessed based on the presence or absence of foods or beverages during self-classification of the meal occasion (breakfast, lunch, dinner, snack) during dietary recalls.

Diet quality was assessed using the Healthy Eating Index (HEI)-2015, which measures the alignment of dietary intakes with the 2015-2020 Dietary Guidelines for Americans (DGA) [27]. The HEI-2015 features 13 graded components and operates on a 100-point scale for maximum score. This density-based scale measures amounts per $1000 \mathrm{kcal}$, with higher 
scores on each of the subscales and the total score represent better diet quality related to the DGA. For a metric of comparison of nutrient intakes to reference standards to identify potential gaps, the percent of participants meeting the Estimated Average Requirement (EAR) or Adequate Intake (AI) for select nutrients were classified from the day of intake.

\subsection{Protein Intake Recommendations}

To assess dietary differences for those who were below protein intake recommendations on the day of intake, protein intake estimations and measured body weights were used to stratify each participant as either meeting or being below the protein recommendation of $0.8 \mathrm{~g}$ of dietary protein per kilogram of body weight per day $(0.8 \mathrm{~g} / \mathrm{kg} /$ day) [28].

\subsection{Physical Functioning}

Data from the physical functioning questionnaire were used to identify self-reported physical limitations for 19 discrete physical tasks. The questionnaire was conducted by trained interviewers in participants' homes and utilized the Computer-Assisted Personal Interview system. The numbers of physical limitations reported was calculated as the sum of physical activities that was reported as a limitation for each individual. Combined isometric grip strength $(\mathrm{kg})$ was calculated by averaging all dynamometer results for each participant ( 3 measurements per hand) to assess a direct function strength measure.

\subsection{Statistical Analyses}

The 2005-2016 NHANES data were gathered from publicly available sources and imported into SPSS (version 25, IBM SPSS Inc., Chicago, IL, USA). Weighted populationbased estimates were calculated using sample weights, clusters, and strata provided by the Centers for Disease Control and Prevention's National Center for Health Statistics. Analyses were conducted with SPSS Complex Samples to generate nationally representative estimates.

This cross-sectional analysis categorized adults aged 31 years and older into levels of glycemic control (non-diabetes, pre-diabetes, and diabetes) and then further classified by whether recommended protein intakes were met (intake $\geq 0.8 \mathrm{~g} / \mathrm{kg} /$ day) or not met (intake $<0.8 \mathrm{~g} / \mathrm{kg} /$ day). Analysis of covariance was performed to test for differences in energy and nutrient intakes, diet quality, and the number of limitations per group across glycemic and protein groups, controlled for sex, race, ethnicity, marital status, and percent of federal poverty rate. Frequency analyses were used to identify weighted population percents of adults meeting DRI reference intakes and those experiencing physical limitations per protein and glycemic stratification. To account for multiple comparisons, significance was set a priori at $\alpha \leq 0.01$.

\section{Results}

\subsection{Demographics}

Data from 23,487 adults aged 31 years and older were stratified into non-diabetes $(n=14,730)$, pre-diabetes $(n=5869)$, and diabetes $(n=2888)$ based on A1c values and further categorized into protein intake groups (not met $<0.8 \mathrm{~g} / \mathrm{kg} /$ day: $n=9514 ;$ met $\geq 0.8 \mathrm{~g} / \mathrm{kg} /$ day: $n=13,973$; Table 1). Overall, $51.2 \%$ of those with diabetes, $45.4 \%$ of those with pre-diabetes and $34.2 \%$ of those without diabetes did not meet the individual protein recommendation. Across all glycemic groups, more males ( $73 \%$ of non-diabetes, $62 \%$ of pre-diabetes, and $57 \%$ of diabetes) met the protein intake recommendations compared to females $(60 \%$ of non-diabetes, $49 \%$ of pre-diabetes, and $39 \%$ of diabetes). A greater proportion of participants did not meet protein intake recommendations for both sexes in the diabetes group ( $43 \%$ of males and $61 \%$ of females) compared to the non-diabetes ( $27 \%$ of males and $40 \%$ of females) and pre-diabetes groups ( $38 \%$ of males and $52 \%$ of females). The mean BMIs for participants who did not meet the protein recommendations was higher across all groups than that of adults who met protein recommendations. Non-Hispanic blacks and participants who were single, divorced, or widowed were least likely to meet protein recommendations across all glycemic groups. 
Table 1. Personal and demographic characteristics in US adults by diabetes status, stratified by intakes above or below protein intake recommendations from the dietary recall.

\begin{tabular}{|c|c|c|c|c|c|c|c|}
\hline \multirow[b]{3}{*}{ Characteristic } & \multirow[b]{3}{*}{ Category } & \multicolumn{2}{|c|}{ Non-Diabetes } & \multicolumn{2}{|c|}{ Pre-Diabetes } & \multicolumn{2}{|c|}{ Diabetes } \\
\hline & & \multicolumn{2}{|c|}{ Protein Intake ${ }^{a}$} & \multicolumn{2}{|c|}{ Protein Intake $^{a}$} & \multicolumn{2}{|c|}{ Protein Intake $^{a}$} \\
\hline & & $\begin{array}{c}<0.8 \mathrm{~g} / \mathrm{kg} / \text { day } \\
\quad(n=5283)\end{array}$ & $\begin{array}{c}\geq 0.8 \mathrm{~g} / \mathrm{kg} / \mathrm{day} \\
\quad(n=9447)\end{array}$ & $\begin{array}{c}<0.8 \mathrm{~g} / \mathrm{kg} / \text { day } \\
\quad(n=2749)\end{array}$ & $\begin{array}{c}\geq 0.8 \mathrm{~g} / \mathrm{kg} / \text { day } \\
\quad(n=3120)\end{array}$ & $\begin{array}{c}<0.8 \mathrm{~g} / \mathrm{kg} / \mathrm{day} \\
\quad(n=1482)\end{array}$ & $\begin{array}{c}\geq 0.8 \mathrm{~g} / \mathrm{kg} / \mathrm{day} \\
\quad(n=1406)\end{array}$ \\
\hline & & \multicolumn{6}{|c|}{$n(\%)$} \\
\hline Total & & $5283(34.2 \%)$ & $9447(65.8 \%)$ & $2749(45.4 \%)$ & $3120(54.6 \%)$ & $1482(51.2 \%)$ & $1406(48.8 \%)$ \\
\hline Gender & Male & $2077(27.2 \%)$ & $5033(72.8 \%)$ & $1158(38.4 \%)$ & $1693(61.6 \%)$ & $679(42.9 \%)$ & $845(57.1 \%)$ \\
\hline & Female & $3206(40.4 \%)$ & $4414(59.6 \%)$ & $1591(51.5 \%)$ & $1427(48.5 \%)$ & $803(60.7 \%)$ & $561(39.3 \%)$ \\
\hline \multirow{5}{*}{ Race/Ethnicity } & Mexican American & $668(30.4 \%)$ & $1456(69.6 \%)$ & $346(38.2 \%)$ & $537(61.8 \%)$ & $273(42.5 \%)$ & $343(57.5 \%)$ \\
\hline & Other Hispanic & $472(32.6 \%)$ & $884(67.4 \%)$ & $266(43.6 \%)$ & $324(56.4 \%)$ & $138(40.1 \%)$ & $176(59.9 \%)$ \\
\hline & Non-Hispanic White & $2707(34.0 \%)$ & $4829(66.0 \%)$ & $1088(45.4 \%)$ & $1217(54.6 \%)$ & $499(51.3 \%)$ & $443(48.7 \%)$ \\
\hline & Non-Hispanic Black & $1111(46.5 \%)$ & $1320(53.5 \%)$ & $862(54.1 \%)$ & $718(45.9 \%)$ & $471(62.7 \%)$ & $297(37.3 \%)$ \\
\hline & Other or Multiracial & $325(25.7 \%)$ & $958(74.3 \%)$ & $187(37.1 \%)$ & $324(62.9 \%)$ & $101(48.7 \%)$ & $147(51.3 \%)$ \\
\hline \multirow[b]{2}{*}{ Marital Status } & Single/Divorced/Widowed & $2043(39.2 \%)$ & $3002(60.8 \%)$ & $1167(47.8 \%)$ & $1159(52.2 \%)$ & $604(54.0 \%)$ & $519(46.0 \%)$ \\
\hline & Married/Living as Married & $3239(31.9 \%)$ & $6442(68.1 \%)$ & $1581(44.1 \%)$ & $1961(55.9 \%)$ & $877(49.8 \%)$ & $885(50.2 \%)$ \\
\hline \multirow{5}{*}{$\begin{array}{l}\text { Highest } \\
\text { Education } \\
\text { Completion }\end{array}$} & $<9$ th grade & $540(37.8 \%)$ & $867(62.2 \%)$ & $434(49.3 \%)$ & $436(50.7 \%)$ & $295(50.6 \%)$ & $284(49.4 \%)$ \\
\hline & $9-11$ th grade & $763(38.0 \%)$ & $1195(62.0 \%)$ & $452(47.3 \%)$ & $471(52.7 \%)$ & $273(53.6 \%)$ & $234(46.4 \%)$ \\
\hline & HS/GED & $1247(38.4 \%)$ & $1965(61.6 \%)$ & $694(47.5 \%)$ & $756(52.5 \%)$ & $336(51.9 \%)$ & $319(48.1 \%)$ \\
\hline & $\begin{array}{c}\text { Some college/Associate's } \\
\text { degree }\end{array}$ & $1600(38.2 \%)$ & $2526(61.8 \%)$ & $702(45.9 \%)$ & $827(54.1 \%)$ & $405(53.8 \%)$ & $343(46.2 \%)$ \\
\hline & College grad & $1129(26.4 \%)$ & $2890(73.6 \%)$ & $464(40.1 \%)$ & $626(59.9 \%)$ & $172(44.2 \%)$ & $223(55.8 \%)$ \\
\hline \multirow{4}{*}{$\begin{array}{l}\text { Meal consumed } \\
(\%)\end{array}$} & Breakfast & $4357(32.5 \%)$ & $8451(67.5 \%)$ & $2343(43.8 \%)$ & $2866(56.2 \%)$ & $1284(50.3 \%)$ & $1284(49.7 \%)$ \\
\hline & Lunch & $3619(30.8 \%)$ & $7526(69.2 \%)$ & $1854(42.4 \%)$ & $2443(57.6 \%)$ & $999(49.1 \%)$ & $1084(50.9 \%)$ \\
\hline & Dinner & $4576(32.8 \%)$ & $8781(67.2 \%)$ & $2421(44.7 \%)$ & $2854(55.3 \%)$ & $1295(50.6 \%)$ & $1295(49.4 \%)$ \\
\hline & Snack & $4950(33.9 \%)$ & $8992(66.1 \%)$ & $2540(45.2 \%)$ & $2917(54.8 \%)$ & $1360(50.7 \%)$ & $1324(49.3 \%)$ \\
\hline \multirow{4}{*}{$\begin{array}{l}\text { Number of } \\
\text { meals reported }\end{array}$} & 1 meal & $533(58.3 \%)$ & $357(41.7 \%)$ & $251(69.9 \%)$ & $93(30.1 \%)$ & $115(76.3 \%)$ & $30(23.7 \%)$ \\
\hline & 2 meals & $2117(44.7 \%)$ & $2827(55.3 \%)$ & $1085(52.9 \%)$ & $1005(47.1 \%)$ & $605(53.8 \%)$ & $495(46.2 \%)$ \\
\hline & 3 meals & $2595(27.9 \%)$ & $6249(72.1 \%)$ & $1399(40.2 \%)$ & $2020(59.8 \%)$ & $751(48.0 \%)$ & 881 (52.0\%) \\
\hline & & \multicolumn{6}{|c|}{ Mean $(95 \% \mathrm{CI})$} \\
\hline \multirow{3}{*}{\multicolumn{2}{|c|}{$\begin{array}{c}\text { Age (years) } \\
\text { Poverty-Income Ratio }{ }^{\mathrm{b}} \\
\text { Body Mass Index }\left(\mathrm{kg} / \mathrm{m}^{2}\right)\end{array}$}} & $51.9(51.3,52.5)$ & $49.8(49.2,50.3)$ & $60.1(59.3,61.0)$ & $59.1(58.4,59.8)$ & $59.8(59,60.6)$ & $59(57.9,60.2)$ \\
\hline & & $3.0(2.9,3.1)$ & $3.4(3.3,3.5)$ & $2.7(2.5,2.8)$ & $3.0(2.9,3.1)$ & $2.6(2.4,2.7)$ & $2.8(2.6,2.9)$ \\
\hline & & $30.5(30.3,30.8)$ & $27.0(26.9,27.2)$ & $33.3(32.9,33.8)$ & $29.0(28.7,29.3)$ & $36.0(35.4,36.6)$ & $30.9(30.5,31.3)$ \\
\hline \multicolumn{2}{|c|}{ Weight $(\mathrm{kg})$} & $86.4(85.6,87.2)$ & $77.9(77.4,78.5)$ & $92.7(91.4,94)$ & $81.4(80.4,82.3)$ & $\begin{array}{c}100.6(98.3 \\
102.9)\end{array}$ & $88.0(86.6,89.5)$ \\
\hline
\end{tabular}

${ }^{a}$ Protein intake recommendations computed as either meeting or not meeting $0.8 \mathrm{~g}$ of dietary protein per kilogram of body weight per day.

$\mathrm{b}$ Income reported as a ratio of the federal poverty rate.

\subsection{Dietary Intakes}

For those who met or exceeded the protein intake recommendation on the day of intake, the mean total protein intake was double that of those who did not meet the recommendation (Table 2). Energy-adjusted protein intakes was greater for all groups across glycemic status, with adults with diabetes having the greatest density (46 g protein per $1000 \mathrm{kcal})$. Participants who did not meet protein recommendations consumed significantly less energy for all glycemic groups; $66 \%, 71 \%$ and $65 \%$ of the energy intakes in the nondiabetes, pre-diabetes, and diabetes groups, respectively $(p<0.001)$. Additionally, adults not meeting protein recommendations consumed significantly more total carbohydrate and added sugars across all glycemic groups $(p<0.001)$. Across all glycemic groups, adults below the protein intake recommendation consumed significantly less total fat, saturated fat, monounsaturated fat, choline, vitamin B12, phosphorus, zinc, sodium, and selenium per $1000 \mathrm{kcal}(p \leq 0.007)$.

Many adults below the recommended protein intake did not meet Estimated Average Requirements (EAR) or Adequate Intakes (AI) for fiber ( $\geq 93 \%)$, magnesium $(\geq 82 \%)$, choline ( $\geq 96 \%)$, and vitamins C $(\geq 65 \%)$, D $(\geq 95 \%), E(\geq 92 \%)$, and $K(\geq 78 \%)$ across all glycemic groups (Table 3). Even for those meeting protein recommendations, many participants across glycemic groups did not meet the EAR/AI for fiber $(\geq 79 \%)$, vitamin $\mathrm{C}(\geq 50 \%)$, choline $(\geq 72 \%)$, and vitamins $\mathrm{D}(\geq 84 \%)$, E $(\geq 74 \%)$, and $\mathrm{K}(\geq 62 \%)$. Rates of inadequate intakes were lower from the below protein groups compared to the met protein groups for B vitamins, including niacin, thiamin, riboflavin, vitamin B6 and B12, as well as iron, zinc, magnesium, copper, and selenium. 
Table 2. Differences in energy and energy-adjusted nutrient intakes across diabetes status for those who were below or met the protein intake recommendation from the 2005-2016 National Health and Nutrition Examination Survey (NHANES) ${ }^{\text {a,c }}$.

\begin{tabular}{|c|c|c|c|c|c|c|c|c|c|}
\hline \multirow[b]{3}{*}{ Nutrients ${ }^{b}$} & \multicolumn{3}{|c|}{ Non-Diabetes } & \multicolumn{3}{|c|}{ Pre-Diabetes } & \multicolumn{3}{|c|}{ Diabetes } \\
\hline & \multicolumn{3}{|c|}{ Protein Intake ${ }^{a, c}$} & \multicolumn{3}{|c|}{ Protein Intake ${ }^{a, c}$} & \multicolumn{3}{|c|}{ Protein Intake ${ }^{a, c}$} \\
\hline & $\begin{array}{c}<0.8 \mathrm{~g} / \mathrm{kg} / \mathrm{day} \\
(n=5283)\end{array}$ & $\begin{array}{c}\geq 0.8 \mathrm{~g} / \mathrm{kg} / \mathrm{day} \\
(n=9447)\end{array}$ & $p$ & $\begin{array}{c}<0.8 \mathrm{~g} / \mathrm{kg} / \mathrm{day} \\
(n=2749)\end{array}$ & $\begin{array}{c}\geq 0.8 \mathrm{~g} / \mathrm{kg} / \mathrm{day} \\
\quad(n=3120)\end{array}$ & $p$ & $\begin{array}{c}<0.8 \mathrm{~g} / \mathrm{kg} / \mathrm{day} \\
\quad(n=1482)\end{array}$ & $\begin{array}{c}\geq 0.8 \mathrm{~g} / \mathrm{kg} / \mathrm{day} \\
(n=1406)\end{array}$ & $p$ \\
\hline Energy (kcal) & $1609(12)$ & $2444(15)$ & $<0.001$ & 1640 (19) & $2318(21)$ & $<0.001$ & $1551(25)$ & $2391(39)$ & $<0.001$ \\
\hline Protein, total (g) & $52.1(0.5)$ & $100.2(0.6)$ & $<0.001$ & $54.4(0.7)$ & $98.2(0.8)$ & $<0.001$ & $56.2(0.9)$ & $104(1.8)$ & $<0.001$ \\
\hline \multicolumn{10}{|l|}{ Energy-adjusted intakes } \\
\hline Protein (g) & $33.7(0.2)$ & $42.8(0.2)$ & $<0.001$ & $34.7(0.3)$ & $44.3(0.3)$ & $<0.001$ & $38.1(0.5)$ & $45.6(0.5)$ & $<0.001$ \\
\hline Carbohydrate (g) & $129(0.8)$ & $116(0.5)$ & $<0.001$ & $130(0.9)$ & $117(0.8)$ & $<0.001$ & $126(0.9)$ & $112(0.9)$ & $<0.001$ \\
\hline Added sugars (g) & $37.4(0.6)$ & $28.9(0.4)$ & $<0.001$ & $36.3(0.8)$ & $28.2(0.7)$ & $<0.001$ & $30.5(1)$ & $22.0(0.7)$ & $<0.001$ \\
\hline Dietary fiber (g) & $8.5(0.1)$ & $8.4(0.1)$ & 0.526 & $8.6(0.1)$ & $8.7(0.1)$ & 0.569 & $8.9(0.2)$ & $9.0(0.3)$ & 0.732 \\
\hline Total fat $(\mathrm{g})$ & $35.8(0.2)$ & $37.9(0.2)$ & $<0.001$ & $36.7(0.3)$ & $39(0.3)$ & $<0.001$ & $37.9(0.4)$ & $41.2(0.4)$ & $<0.001$ \\
\hline Saturated fat (g) & $11.4(0.1)$ & $12.2(0.1)$ & $<0.001$ & $11.8(0.1)$ & $12.7(0.1)$ & $<0.001$ & $12.2(0.2)$ & $13.3(0.2)$ & $<0.001$ \\
\hline Monounsaturated fat (g) & $12.8(0.1)$ & $13.7(0.1)$ & $<0.001$ & $13(0.1)$ & $14.1(0.1)$ & $<0.001$ & $13.5(0.2)$ & $14.9(0.2)$ & $<0.001$ \\
\hline Polyunsaturated fat (g) & $8.5(0.1)$ & $8.6(0.1)$ & 0.160 & $8.6(0.1)$ & $8.7(0.1)$ & 0.489 & $8.7(0.1)$ & $9.3(0.1)$ & 0.002 \\
\hline Vitamin A, RAE ( $\mu \mathrm{g})$ & $313(9.0)$ & $323(5.0)$ & 0.274 & $297(8.0)$ & $363(20.0)$ & 0.002 & $345(14.0)$ & $358(15.0)$ & 0.484 \\
\hline Folate ( $\mu$ g DFE) & $263(4.0)$ & $255(2.0)$ & 0.046 & $262(5.0)$ & $261(4.0)$ & 0.766 & $279(8.0)$ & $270(7.0)$ & 0.285 \\
\hline Choline (mg) & $147(2.0)$ & $171(1.0)$ & $<0.001$ & $150(2.0)$ & $181(2.0)$ & $<0.001$ & $163(3.0)$ & $187(3.0)$ & $<0.001$ \\
\hline Vitamin $B_{12}(\mu g)$ & $2.3(0.1)$ & $2.6(0.0)$ & $<0.001$ & $2.2(0.1)$ & $2.8(0.2)$ & $<0.001$ & $2.5(0.1)$ & $3.0(0.1)$ & 0.007 \\
\hline Vitamin C (mg) & $48.5(1.4)$ & $42.2(0.7)$ & $<0.001$ & $45.2(1.2)$ & $43.0(1.2)$ & 0.180 & $48.0(2.0)$ & $38.8(1.3)$ & $<0.001$ \\
\hline Vitamin D $(\mu \mathrm{g})$ & $2.0(0.1)$ & $2.5(0.1)$ & $<0.001$ & $1.9(0.1)$ & $2.6(0.1)$ & $<0.001$ & $2.4(0.2)$ & $2.7(0.1)$ & 0.134 \\
\hline Vitamin K $(\mu \mathrm{g})$ & $62.8(2.4)$ & $61.8(2.0)$ & 0.730 & $56.8(2.7)$ & $64.5(2.5)$ & 0.028 & $62.2(4.3)$ & $65(4.2)$ & 0.588 \\
\hline Calcium (mg) & $440(5.0)$ & $463(4.0)$ & $<0.001$ & $433(5.0)$ & $462(6.0)$ & $<0.001$ & $496(14.0)$ & $490(7.0)$ & 0.697 \\
\hline Phosphorus (mg) & $599(4.0)$ & $683(3.0)$ & $<0.001$ & $598(4.0)$ & $696(5.0)$ & $<0.001$ & $655(8.0)$ & $734(8.0)$ & $<0.001$ \\
\hline Magnesium (mg) & $151(1.0)$ & $154(1.0)$ & 0.037 & $146(2.0)$ & $151(1.0)$ & 0.003 & $150(3.0)$ & $154(2.0)$ & 0.205 \\
\hline Iron (mg) & $7.2(0.1)$ & $7.2(0.1)$ & 0.736 & $7.3(0.1)$ & $7.6(0.1)$ & 0.168 & $7.9(0.2)$ & $7.9(0.2)$ & 0.954 \\
\hline Zinc (mg) & $4.9(0.1)$ & $5.8(0.01)$ & $<0.001$ & $5.1(0.1)$ & $6(0.1)$ & $<0.001$ & $5.5(0.1)$ & $6.7(0.3)$ & $<0.001$ \\
\hline Copper (mg) & $0.65(0.01)$ & $0.66(0.01)$ & 0.057 & $0.64(0.01)$ & $0.68(0.03)$ & 0.205 & $0.66(0.01)$ & $0.7(0.02)$ & 0.061 \\
\hline Sodium (mg) & $1617(12.0)$ & $1691(10.0)$ & $<0.001$ & $1665(17.0)$ & $1770(14.0)$ & $<0.001$ & $1764(23.0)$ & $1868(28.0)$ & 0.002 \\
\hline Potassium (mg) & $1330(12.0)$ & $1348(8.0)$ & 0.211 & $1327(15.0)$ & $1384(11.0)$ & 0.002 & $1399(30.0)$ & 1407 (18.0) & 0.795 \\
\hline Selenium $(\mu \mathrm{g})$ & $47.7(0.4)$ & $57.9(0.3)$ & $<0.001$ & $49.7(0.6)$ & $60.1(0.5)$ & $<0.001$ & $54.2(0.8)$ & $62.5(0.8)$ & $<0.001$ \\
\hline
\end{tabular}

${ }^{a}$ Mean (SE) intakes adjusted for race/ethnicity, gender, marital status and percent of federal poverty rate. ${ }^{b}$ Nutrients presented as energy-adjusted intakes per $1000 \mathrm{kcal}$. ${ }^{\mathrm{c}}$ Protein intake recommendations computed as either meeting or not meeting $0.8 \mathrm{~g}$ of dietary protein per kilogram of body weight per day.

Table 3. Proportion consuming less than the Recommended Intakes across diabetes categories and not meeting the protein recommendation.

\begin{tabular}{|c|c|c|c|c|c|c|}
\hline \multirow[b]{3}{*}{ Nutrient $^{a}$} & \multicolumn{2}{|c|}{ Non-Diabetes } & \multicolumn{2}{|c|}{ Pre-Diabetes } & \multicolumn{2}{|c|}{ Diabetes } \\
\hline & \multicolumn{2}{|c|}{ Protein Intake $^{b}$} & \multicolumn{2}{|c|}{ Protein Intake $^{\mathbf{b}}$} & \multicolumn{2}{|c|}{ Protein Intake $^{b}$} \\
\hline & $\begin{array}{c}<0.8 \mathrm{~g} / \mathrm{kg} / \mathrm{day} \\
\quad(n=5283)\end{array}$ & $\begin{array}{c}\geq 0.8 \mathrm{~g} / \mathrm{kg} / \mathrm{day} \\
(n=9447)\end{array}$ & $\begin{array}{c}<0.8 \mathrm{~g} / \mathrm{kg} / \mathrm{day} \\
\quad(n=2749)\end{array}$ & $\begin{aligned} \geq 0.8 \mathrm{~g} / \mathrm{kg} / \mathrm{day} \\
(n=3120)\end{aligned}$ & $\begin{array}{c}<0.8 \mathrm{~g} / \mathrm{kg} / \mathrm{day} \\
\quad(n=1482)\end{array}$ & $\begin{aligned} \geq & 0.8 \mathrm{~g} / \mathrm{kg} / \mathrm{day} \\
& (n=1406)\end{aligned}$ \\
\hline Carbohydrate & 589 (11.1\%) & $208(2.6 \%)$ & $285(9.6 \%)$ & $74(2.1 \%)$ & $217(13.4 \%)$ & $36(2.7 \%)$ \\
\hline Fiber & $5006(94.2 \%)$ & $7720(81.3 \%)$ & $2579(93.4 \%)$ & $2489(79.2 \%)$ & $1378(93.1 \%)$ & $1122(82.1 \%)$ \\
\hline Thiamin & $2299(41.4 \%)$ & $921(9.1 \%)$ & $1123(36.2 \%)$ & $315(9.7 \%)$ & $569(33.5 \%)$ & $118(7.1 \%)$ \\
\hline Riboflavin & $1487(23.1 \%)$ & $336(2.6 \%)$ & 757 (21.8\%) & $121(2.2 \%)$ & $383(20.2 \%)$ & $50(3.1 \%)$ \\
\hline Niacin & $1564(26.1 \%)$ & $193(1.9 \%)$ & $775(24.3 \%)$ & $70(2.1 \%)$ & $397(21.2 \%)$ & $23(1.8 \%)$ \\
\hline Vitamin $\mathrm{B}_{6}$ & 2847 (51.1\%) & $1075(10.4 \%)$ & $1549(52.5 \%)$ & $486(14.6 \%)$ & $869(54.2 \%)$ & 187 (12.3\%) \\
\hline Folate & $2614(47.0 \%)$ & $1727(18.1 \%)$ & $1322(45.8 \%)$ & $600(18.0 \%)$ & $721(46.0 \%)$ & 248 (17.1\%) \\
\hline Vitamin $B_{12}$ & $2291(40.9 \%)$ & $1044(10.0 \%)$ & $1139(37.8 \%)$ & $357(11.0 \%)$ & $577(35.6 \%)$ & $172(9.4 \%)$ \\
\hline Vitamin C & $3411(65.4 \%)$ & $4807(50.1 \%)$ & $1722(64.6 \%)$ & $1580(50.7 \%)$ & $986(65.7 \%)$ & 739 (53.3\%) \\
\hline Choline & $5144(97.5 \%)$ & $7034(75.1 \%)$ & $2655(95.8 \%)$ & $2358(76.6 \%)$ & $1431(96.0 \%)$ & $1009(71.7 \%)$ \\
\hline Vitamin A & $3863(70.8 \%)$ & $4600(44.8 \%)$ & $1958(68.9 \%)$ & $1523(43.2 \%)$ & $1098(68.7 \%)$ & $725(46.3 \%)$ \\
\hline Vitamin D & $4324(96.8 \%)$ & $6776(85.7 \%)$ & $2398(97.4 \%)$ & $2397(84.2 \%)$ & $1278(95.1 \%)$ & $1072(85.8 \%)$ \\
\hline Vitamin E & $4920(92.0 \%)$ & $7211(73.5 \%)$ & $2576(92.9 \%)$ & $2499(77.6 \%)$ & $1393(91.5 \%)$ & $1126(75.3 \%)$ \\
\hline Vitamin K & $4284(78.1 \%)$ & $6137(61.6 \%)$ & 2197 (78.7\%) & $2030(61.9 \%)$ & $1205(79.0 \%)$ & $928(62.8 \%)$ \\
\hline Calcium & $4108(74.5 \%)$ & $3818(36.7 \%)$ & $2179(77.5 \%)$ & $1501(45.5 \%)$ & $1163(75.9 \%)$ & 657 (40.6\%) \\
\hline Phosphorus & $1116(18.4 \%)$ & $32(0.3 \%)$ & $550(17.0 \%)$ & $10(0.2 \%)$ & $275(14.2 \%)$ & $3(0.1 \%)$ \\
\hline Magnesium & $4459(82.6 \%)$ & $4091(40.1 \%)$ & $2336(82.2 \%)$ & $1496(46.3 \%)$ & $1285(84.7 \%)$ & $681(46.3 \%)$ \\
\hline Iron & $1313(23.8 \%)$ & $300(3.1 \%)$ & 487 (14.7\%) & $68(1.9 \%)$ & $255(15.3 \%)$ & $21(1.2 \%)$ \\
\hline Zinc & $3530(62.8 \%)$ & $1453(13.0 \%)$ & $1732(58.2 \%)$ & $566(15.8 \%)$ & $942(57.7 \%)$ & $209(12.3 \%)$ \\
\hline Copper & $1944(33.1 \%)$ & $561(4.9 \%)$ & $926(31.5 \%)$ & $236(6.5 \%)$ & $505(30.4 \%)$ & $85(4.4 \%)$ \\
\hline Selenium & $1259(22.7 \%)$ & $66(0.7 \%)$ & $558(17.2 \%)$ & $11(0.4 \%)$ & $277(15.4 \%)$ & $2(0.6 \%)$ \\
\hline
\end{tabular}

${ }^{a}$ Number; $\mathrm{n}$ (\% of total). For nutrients without an Estimated Average Requirement, the Adequate Intake is used, italicized above. ${ }^{b}$ Protein intake recommendations computed as either meeting or not meeting $0.8 \mathrm{~g}$ of dietary protein per kilogram of body weight per day. 


\subsection{Diet Quality}

Across all glycemic groups, total diet quality was poorer in adults below the protein intake recommendation $(p<0.001$; Table 4$)$. HEI scores were less than $70 \%$ of the ideal score for greens and beans, whole grains, dairy, seafood and plant proteins, fatty acids, refined grains, sodium, and saturated fat. Those that met the protein intake recommendation had significantly poorer HEI scores for sodium and saturated fat across all glycemic levels $(p<0.001)$. Adults with diabetes who met protein recommendations had better HEI-2015 scores for total vegetables, whole grains, dairy, and added sugars than any other group, and in contrast, they had the poorest HEI-2015 score for sodium.

Table 4. Differences in Healthy Eating Index 2015 scores across diabetes status and in those below or meeting the protein intake recommendation.

\begin{tabular}{|c|c|c|c|c|c|c|c|c|c|}
\hline \multirow[b]{3}{*}{$\begin{array}{l}\text { HEI-2015 Score } \\
\text { (Score Range) }\end{array}$} & \multicolumn{3}{|c|}{ Non-Diabetes } & \multicolumn{3}{|c|}{ Pre-Diabetes } & \multicolumn{3}{|c|}{ Diabetes } \\
\hline & \multicolumn{3}{|c|}{ Protein Intake ${ }^{a, b}$} & \multicolumn{3}{|c|}{ Protein Intake ${ }^{a, b}$} & \multicolumn{3}{|c|}{ Protein Intake ${ }^{a, b}$} \\
\hline & $\begin{array}{c}<0.8 \mathrm{~g} / \mathrm{kg} / \text { day } \\
\quad(n=5283)\end{array}$ & $\begin{array}{c}\geq 0.8 \mathrm{~g} / \mathrm{kg} / \mathrm{day} \\
\quad(n=9447)\end{array}$ & $p$ & $\begin{array}{l}<0.8 \mathrm{~g} / \mathrm{kg} / \mathrm{day} \\
\quad(n=2749)\end{array}$ & $\begin{array}{c}\geq 0.8 \mathrm{~g} / \mathrm{kg} / \mathrm{day} \\
\quad(n=3120)\end{array}$ & $p$ & $\begin{array}{c}<0.8 \mathrm{~g} / \mathrm{kg} / \text { day } \\
\quad(n=1482)\end{array}$ & $\begin{array}{c}\geq 0.8 \mathrm{~g} / \mathrm{kg} / \mathrm{day} \\
(n=1406)\end{array}$ & $p$ \\
\hline Total Fruit (0-5) & $2.1(0.05)$ & $2.2(0.03)$ & 0.174 & $2.3(0.07)$ & $2.3(0.06)$ & 0.664 & $2.2(0.09)$ & $2.1(0.08)$ & 0.565 \\
\hline Whole Fruit (0-5) & $2.0(0.1)$ & $2.2(0.01)$ & $<0.001$ & $2.2(0.1)$ & $2.4(0.1)$ & 0.033 & $2.2(0.1)$ & $2.3(0.1)$ & 0.661 \\
\hline Total Vegetables (0-5) & $3.0(0.01)$ & $3.2(0.01)$ & $<0.001$ & $3.1(0.01)$ & $3.2(0.01)$ & 0.009 & $3.1(0.1)$ & $3.4(0.1)$ & $<0.001$ \\
\hline Greens \& Beans (0-5) & $1.4(0.01)$ & $1.8(0.01)$ & $<0.001$ & $1.3(0.1)$ & $1.8(0.1)$ & $<0.001$ & $1.2(0.1)$ & $1.7(0.1)$ & $<0.001$ \\
\hline Whole Grains $(0-10)$ & $2.5(0.1)$ & $2.6(0.1)$ & 0.533 & $2.7(0.1)$ & $2.7(0.1)$ & 0.995 & $2.7(0.1)$ & $2.9(0.2)$ & 0.471 \\
\hline Dairy (0-10) & $4.2(0.1)$ & $5.2(0.1)$ & $<0.001$ & $4.3(0.1)$ & $5.1(0.1)$ & $<0.001$ & $4.6(0.1)$ & $5.5(0.1)$ & $<0.001$ \\
\hline Protein Foods $(0-5)$ & $3.8(0.01)$ & $4.5(0.01)$ & $<0.001$ & $3.9(0.01)$ & $4.6(0.01)$ & $<0.001$ & $4.1(0.1)$ & $4.6(0.01)$ & $<0.001$ \\
\hline $\begin{array}{l}\text { Seafood \& Plant } \\
\text { Proteins }(0-5)\end{array}$ & $2.1(0.1)$ & $2.7(0.01)$ & $<0.001$ & $2.1(0.1)$ & $2.6(0.1)$ & $<0.001$ & $1.9(0.1)$ & $2.6(0.1)$ & $<0.001$ \\
\hline Fatty Acids (0-10) & $5.4(0.1)$ & $5.1(0.1)$ & 0.001 & $5.2(0.1)$ & $5.0(0.1)$ & 0.339 & $5.3(0.1)$ & $5.0(0.1)$ & 0.299 \\
\hline Refined Grains $(0-10)^{c}$ & $6.2(0.1)$ & $6.5(0.1)$ & 0.014 & $5.9(0.1)$ & $6.4(0.1)$ & 0.002 & $5.6(0.1)$ & $6.0(0.2)$ & 0.123 \\
\hline Sodium $(0-10)^{c}$ & $5.0(0.1)$ & $4.4(0.1)$ & $<0.001$ & $4.6(0.1)$ & $3.8(0.1)$ & $<0.001$ & $4.0(0.1)$ & $3.2(0.1)$ & $<0.001$ \\
\hline Added Sugars $(0-10)^{c}$ & $5.9(0.1)$ & $7.1(0.1)$ & $<0.001$ & $6.1(0.1)$ & $7.2(0.1)$ & $<0.001$ & $6.9(0.1)$ & $8.1(0.1)$ & $<0.001$ \\
\hline Saturated Fat $(0-10)^{c}$ & $6.6(0.1)$ & $6.0(0.1)$ & $<0.001$ & $6.3(0.1)$ & $5.7(0.1)$ & $<0.001$ & $6.0(0.1)$ & $5.2(0.1)$ & $<0.001$ \\
\hline Total HEI Score (0-100) & $50.4(0.3)$ & $53.5(0.2)$ & $\begin{array}{c}< \\
0.001\end{array}$ & $49.9(0.4)$ & $52.8(0.4)$ & $<0.001$ & $49.9(0.5)$ & $52.6(0.5)$ & $<0.001$ \\
\hline
\end{tabular}

${ }^{a}$ Mean (SE) intakes adjusted for race/ethnicity, gender, marital status and percent of federal poverty rate. ${ }^{\mathrm{b}}$ Protein intake recommendations computed as either meeting or not meeting $0.8 \mathrm{~g}$ of dietary protein per kilogram of body weight per day. ${ }^{\mathrm{c}}$ Higher scores for scales related to moderation represent lower intakes.

\subsection{Physical Functioning Limitations}

Adults with diabetes had greater frequency of physical limitations than those with nondiabetes, as did adults with pre-diabetes, regardless of protein intake category (Table 5). Those not meeting protein recommendations reported significantly more numbers of physical limitations than those who met protein recommendation across all levels of glycemia. Physical limitations were more prevalent in adults with protein intakes below $0.8 \mathrm{~g} / \mathrm{kg} /$ day compared to those who met (or exceeded) this recommendation across all glycemic groups. The most common limitations across all groups included: stooping, crouching, and kneeling; standing for long periods; and pushing or pulling large objects. More than half $(52 \%)$ of the diabetes population that was below protein recommendations reported physical limitations for stooping, crouching, and kneeling.

Grip strength and number of physical limitations were analyzed for both adjusted and unadjusted results. Unadjusted data reveal greater grip strength among individuals who met protein recommendations compared to those below protein recommendations across all glycemic groups. Adults in the non-diabetes group had the greatest overall grip strength compared to those with pre-diabetes and diabetes. After controlling for factors related to diet quality and diabetes, mean grip strength was lowest in the diabetes groups. 
Table 5. Frequency of limitations and grip strength differences across diabetes status in those below or meeting the protein intake recommendation.

\begin{tabular}{|c|c|c|c|c|c|c|}
\hline \multirow[b]{3}{*}{ Limitations Experienced $^{b}$} & \multicolumn{2}{|c|}{ Non-Diabetes } & \multicolumn{2}{|c|}{ Pre-Diabetes } & \multicolumn{2}{|c|}{ Diabetes } \\
\hline & \multicolumn{2}{|c|}{ Protein Intake $^{a}$} & \multicolumn{2}{|c|}{ Protein Intake $^{a}$} & \multicolumn{2}{|c|}{ Protein Intake ${ }^{a}$} \\
\hline & $\begin{array}{c}<0.8 \mathrm{~g} / \mathrm{kg} / \mathrm{day} \\
\quad(n=5283)\end{array}$ & $\begin{array}{l}\geq 0.8 \mathrm{~g} / \mathrm{kg} / \mathrm{day} \\
\quad(n=9447)\end{array}$ & $\begin{array}{c}<0.8 \mathrm{~g} / \mathrm{kg} / \mathrm{day} \\
\quad(n=2749)\end{array}$ & $\begin{array}{l}\geq 0.8 \mathrm{~g} / \mathrm{kg} / \mathrm{day} \\
\quad(n=3120)\end{array}$ & $\begin{array}{c}<0.8 \mathrm{~g} / \mathrm{kg} / \mathrm{day} \\
\quad(n=1482)\end{array}$ & $\begin{aligned} \geq & 0.8 \mathrm{~g} / \mathrm{kg} / \mathrm{day} \\
& (n=1406)\end{aligned}$ \\
\hline & \multicolumn{6}{|c|}{$\mathrm{n}(\%)$} \\
\hline Stooping, crouching, kneeling & $1520(29.0 \%)$ & $1603(17.0 \%)$ & $1104(40.8 \%)$ & $930(30.1 \%)$ & $760(52.0 \%)$ & $488(35.3 \%)$ \\
\hline Standing for long periods & $1346(25.8 \%)$ & $1440(15.4 \%)$ & $968(35.9 \%)$ & $817(26.5 \%)$ & $676(46.9 \%)$ & $422(30.6 \%)$ \\
\hline Push or pull large objects & $1120(21.7 \%)$ & $1216(13.0 \%)$ & $784(29.7 \%)$ & $695(22.8 \%)$ & $570(40.5 \%)$ & $343(25.2 \%)$ \\
\hline Lifting or carrying & $793(15.1 \%)$ & $815(8.7 \%)$ & $587(21.7 \%)$ & $484(15.7 \%)$ & $447(30.6 \%)$ & $267(19.3 \%)$ \\
\hline Standing up from armless chair & $763(14.5 \%)$ & $750(7.9 \%)$ & $581(21.2 \%)$ & $436(14.0 \%)$ & $468(31.6 \%)$ & $267(19.0 \%)$ \\
\hline House chores & $750(14.4 \%)$ & $782(8.4 \%)$ & $556(20.9 \%)$ & $416(13.7 \%)$ & $451(32.0 \%)$ & $230(16.9 \%)$ \\
\hline Sitting for long periods & $739(14.0 \%)$ & $893(9.5 \%)$ & $536(19.5 \%)$ & $418(13.4 \%)$ & $412(28.0 \%)$ & $241(17.2 \%)$ \\
\hline Going out to movies, events & $637(12.3 \%)$ & $677(7.2 \%)$ & $468(17.6 \%)$ & $318(10.4 \%)$ & $396(27.8 \%)$ & $206(15.1 \%)$ \\
\hline Walking for a quarter mile & $576(12.3 \%)$ & $584(6.6 \%)$ & $461(20.5 \%)$ & $336(12.2 \%)$ & $274(25.7 \%)$ & $187(15.8 \%)$ \\
\hline Reaching up over head & $628(11.9 \%)$ & $644(6.8 \%)$ & $448(16.3 \%)$ & $354(11.4 \%)$ & $358(24.3 \%)$ & $238(17.0 \%)$ \\
\hline Getting in and out of bed & $601(11.4 \%)$ & $609(6.4 \%)$ & $419(15.3 \%)$ & $318(10.2 \%)$ & $385(26.1 \%)$ & $203(14.5 \%)$ \\
\hline Attending social event & $500(9.8 \%)$ & $549(5.9 \%)$ & $361(13.8 \%)$ & $253(8.4 \%)$ & $290(20.9 \%)$ & $154(11.5 \%)$ \\
\hline Grasp/holding small objects & $500(9.5 \%)$ & $647(6.9 \%)$ & $366(13.3 \%)$ & $319(10.2 \%)$ & $296(20.0 \%)$ & $181(12.9 \%)$ \\
\hline Walking up ten steps & $422(9.0 \%)$ & $393(4.4 \%)$ & $312(13.8 \%)$ & $235(8.5 \%)$ & $204(19.0 \%)$ & $133(11.2 \%)$ \\
\hline Dressing yourself & $424(8.0 \%)$ & $442(4.7 \%)$ & $326(11.9 \%)$ & $245(7.9 \%)$ & $304(20.6 \%)$ & $179(12.7 \%)$ \\
\hline Walking between rooms (same floor) & $314(5.9 \%)$ & $307(3.3 \%)$ & $270(9.8 \%)$ & $174(5.6 \%)$ & $240(16.2 \%)$ & $120(8.6 \%)$ \\
\hline Preparing meals & $296(5.7 \%)$ & $324(3.5 \%)$ & $230(8.7 \%)$ & $159(5.3 \%)$ & $201(14.4 \%)$ & $99(7.3 \%)$ \\
\hline Leisure activity at home & $243(4.6 \%)$ & $261(2.8 \%)$ & $164(6.0 \%)$ & $119(3.8 \%)$ & $150(10.2 \%)$ & $98(7.0 \%)$ \\
\hline \multirow[t]{2}{*}{ Using fork, knife, drinking from cup } & $165(3.1 \%)$ & $221(2.3 \%)$ & $135(4.9 \%)$ & $94(3.0 \%)$ & $109(7.4 \%)$ & $70(5.0 \%)$ \\
\hline & \multicolumn{6}{|c|}{ Mean (SE) } \\
\hline Number of Limitations (unadjusted) & $2.0(0.1)$ & $1.2(0.05)$ & $3.1(0.1)$ & $2.1(0.1)$ & $4.5(0.2)$ & $2.7(0.2)$ \\
\hline Number of Limitations (adjusted) & $1.7(0.05)$ & $1.3(0.05)$ * & $2.8(0.1)$ & $2.3(0.1)$ * & $4.3(0.2)$ & $2.9(0.2) *$ \\
\hline $\begin{array}{c}\text { Combined Grip Strength } \\
(\mathrm{kg}, \text { unadjusted })\end{array}$ & $70.3(0.9)$ & $74.1(0.5) *$ & $67.8(1.5)$ & $69.6(1.0)$ & $66.0(1.8)$ & $70.0(1.5)$ \\
\hline $\begin{array}{l}\text { Combined Grip Strength } \\
(\mathrm{kg} \text {, adjusted })\end{array}$ & $73.8(0.5)$ & $72.6(0.4) *$ & $70.9(0.9)$ & $68.0(0.5)$ & $68.0(0.9)$ & $64.6(0.8)$ \\
\hline
\end{tabular}

a Protein intake recommendation computed as $0.8 \mathrm{~g}$ of dietary protein per kilogram of body weight. ${ }^{\mathrm{b}}$ Mean adjusted for race/ethnicity, gender, marital status and percent of federal poverty rate. * Significantly $(p<0.001)$ different between those who met and did not meet the protein intake recommendation within the diabetes category.

\section{Discussion}

Diet quality has been previously examined in the general US population, yet less is known regarding diet quality in the adult population with diabetes [29-33]. Moreover, key components of diet quality, such as protein, likely contribute to physical functioning limitations in this population [18]. Therefore, this study aimed to identify differences in diet quality, nutrient intakes, and physical limitations by protein intake across levels of glycemic control. The current analysis found that adults with protein intakes not meeting the recommendation have poor overall diet quality and greater physical limitations regardless of diabetes status.

To optimize personal functioning and health outcomes from diabetes, medical nutrition therapy (MNT) is included in diabetes care guidelines as a frontline therapy and is recommended for all individuals with prediabetes and diabetes [34,35]. Although nutrition therapy aims to target overall diet quality, it tends to focus nutrition education related to carbohydrate and added sugars intakes, to improve glycemic control [36-38]. While emphasizing the importance of regulating carbohydrate intake and reducing calories is beneficial in this population, it may take attention away from other key components of diet quality, such as fruits, vegetables, and protein. In our analysis adults with diabetes who met protein recommendations had better overall HEI-2015 scores than any other group for total vegetables, whole grains, dairy, and added sugars, highlighting the impact of nutrition education focused on carbohydrate and added sugars. However, our results also indicate that protein choices among adults with diabetes are likely less lean options, consisting of fatty and processed meats, resulting in greater consumption of saturated fat and a reduction 
in diet quality. This underscores the limitations of current nutrition education with respect to the importance of protein intakes, specifically lean and plant-based proteins, especially for cost effective sources for intakes among individuals in a lower socioeconomic status. Considering that adults with diabetes are already at an increased risk for cardiovascular disease, it is important that they choose leaner protein options to decrease saturated fat intake and improve serum lipids and meet protein needs $[39,40]$.

Dietary protein can help with glycemic control as it is insulinotropic [41]. It may help slow gastric emptying, improve glucagon-like peptide 1 (GLP-1) secretion [42], and increase satiety [43]. Additionally, consumption of lean protein may help to improve post-prandial dysmetabolism rather than contribute to blood glucose exacerbations [44]. Our analysis found that adults who met protein intakes generally reported eating less total carbohydrates, whereas adults not meeting these modest protein recommendations relied more heavily on carbohydrates and sugars.

The current study identified that adults who did not meet protein recommendations had poorer nutrient density, overall diet quality, and were more likely to skip meals. These factors likely contribute to greater rates of physical limitations in this population [18]. The number of physical limitations was greatest in adults with diabetes and is likely due to insulin resistance as well as other metabolic derangements [7,10]. Poorer diet quality, and lower intakes of key nutrients, are also likely to negatively impact physical functioning [45] and loss of lean body mass [46].

Typically, the incidence of diabetes is higher in the older population; however, rates are increasing in adults younger than 65 years [1]. While age was not used as a stratification but as a covariate in this analysis, previous findings showed that older adults with poorer protein intakes are more likely to skip meals and have greater rates of physical limitations than those of younger ages [18]. Missing meals creates a lost opportunity for obtaining energy and key nutrients to support normal health and physical function. That analysis was stratified by age only and did include people with diabetes. The compounding accumulation of age, poor diet quality, lower protein intake, and lower energy intake are likely responsible for the greater rates of physical limitations. This reduction in physical function may be considered a major risk factor for sarcopenia [47].

Previous studies have identified associations between sarcopenia and diabetes $[5,48,49]$. Although the exact mechanism is unclear, insulin resistance is associated with loss of muscle tissue even in adults without a diabetes diagnosis [50]. Therefore, while loss of function and sarcopenia continue to be health concerns for older adults, it may be more important for those with diabetes. Sarcopenia is a health concern as it may increase the risk for falls, and subsequently fractures, as well as decreased physical functioning [9] and evidence suggests that adults with diabetes have an increased risk for falls and fractures [51]. Considering the milieu of increased risks for acute and chronic health events in diabetes, a greater emphasis on diet quality and adequate protein is needed.

Prior data has suggested that, at the population level, adults may be consuming sufficient protein, especially amongst males [52]; however, at the individual level, nearly half of adults with diabetes did not meet the recommended protein level on the day of intake. Several groups have encouraged recommendations for higher recommended levels for protein intakes (1.0 or $1.2 \mathrm{~g}$ per kilogram) [53-56]; thus, the proportion of adults not meeting recommended protein intakes on the day of intakes would be greater. These lower protein intakes, especially in adults with diabetes, were associated with poorer diet quality, not meeting nutrient recommendations, and increased numbers of physical limitations compared to those who met or exceeded the protein recommendation. These findings add to the body of evidence that sufficient protein intakes may support functional outcomes while increasing the emphasis on overall diet quality.

These data provide a unique opportunity to assess function status related to dietary intakes in individuals by glycemic level. However, there are limitations to consider when evaluating the data. The dietary intakes represent a single, 24-h recall and cannot be assumed to represent usual intakes do not establish nutrient adequacy and are subject 
to recall bias. The multiple pass method employed in data collection helps improve the accuracy of the reporting [24]. Furthermore, as a cross-sectional analyses, these data do not infer causation of diabetes status, dietary patterns, and physical functioning outcomes, but underscore differences across the groups on the day of intake.

Based on the day of intake, these findings challenge the assumption that all Americans, and especially those with diabetes, are getting enough protein $[57,58]$. Those that did not meet protein intakes on the day of intake had lower energy intakes, but also significantly lower protein intakes per $1000 \mathrm{kcals}$. Assessment on physical function and dietary proteins could be a target of assessment, especially in individuals with comorbidities such as diabetes. These concerns of physical functioning limitations have been seen in as early as middle-aged adults, suggesting screening should not be limited just to the elderly [18]. MNT should emphasize improvement of overall diet quality, including adequate protein intake from a variety of sources. However, due to the frequency of meal skipping, likely related to high professional, social, and familial responsibilities, food intake alone may be insufficient to meet protein and micronutrient needs, while not exceeding energy needs $[18,59]$. Therefore, when dietary intakes may not be sufficient to meet dietary needs for varying reasons, integrating diabetes-specific oral nutrition supplements with regular food intake would increase the likelihood of meeting protein and micronutrient needs [60]. Future research should examine the relationship between protein intakes and falls and fractures among individuals with diabetes. This would contribute to the understanding of associations between nutrition and common consequences of an aging, at-risk group of adults.

\section{Conclusions}

Diet quality was poorer and physical limitations were more prevalent in adults who consumed less than the recommended protein intakes of $0.8 \mathrm{~g} / \mathrm{kg} /$ day. Adults with diabetes had more physical limitations than those with non-diabetes, and adults with diabetes who consumed less protein than recommended had further increased limitations. Considering previous studies demonstrate that adults with diabetes are at an increased risk for muscle loss, adequate protein intake may be a critical nutritional factor to help prevent functional decline and sarcopenia. Therefore, our data support the need for nutrition therapy and emphasis on ensuring protein intakes in the adults with diabetes to support healthy aging and reduce or prevent sarcopenia.

Author Contributions: Conceptualization, O.J.K., J.L.K.-S. and C.A.T.; methodology, C.A.T.; software, C.A.T.; validation S.M.F., O.J.K., J.L.K.-S. and C.A.T.; formal analysis S.M.F. and C.A.T.; investigation S.M.F. and C.A.T.; resources, O.J.K. and C.A.T.; data curation S.M.F. and C.A.T.; writing—original draft preparation S.M.F., O.J.K. and C.A.T.; writing—review and editing, O.J.K., J.L.K.-S. and C.A.T.; visualization S.M.F. and C.A.T.; supervision, C.A.T.; project administration, C.A.T.; funding acquisition, O.J.K., J.L.K.-S. and C.A.T. All authors have read and agreed to the published version of the manuscript.

Funding: This research and APC was funded by Abbott Nutrition, grant number AWD-105203.

Institutional Review Board Statement: The study was conducted according to the guidelines of the Declaration of Helsinki, and approved by the Institutional Review Board (or Ethics Committee) of CDC NCHS Research Ethics Review Board (protocol code Protocols \#2005-06 and \#2011-17).

Informed Consent Statement: Informed consent was obtained from all subjects involved in the study.

Data Availability Statement: Public use data are available from National Center for Health Statistics of the Centers for Disease Control and Prevention.

Conflicts of Interest: O.J.K. was an employee of Abbott Nutrition at the time of the work and collaborated to develop the research questions and contribute to the writing of the manuscript. CT has received speaker honoraria from Abbott Nutrition. 


\section{References}

1. Centers for Disease Control and Prevention. National Diabetes Statistics Report. US. Department of Health and Human Services, Ed.; 2020. Available online: https://www.cdc.gov/diabetes/data/statistics/statistics-report.html (accessed on 26 July 2021 ).

2. Wild, S.; Roglic, G.; Green, A.; Sicree, R.; King, H. Global prevalence of diabetes: Estimates for the year 2000 and projections for 2030. Diabetes Care 2004, 27, 1047-1053. [CrossRef]

3. Zimmet, P.; Alberti, K.G.; Shaw, J. Global and societal of the diabetes epidemic. Nature 2001, 414, 782-787. [CrossRef]

4. Chatterjee, S.; Khunti, K.; Davies, M.J. Type 2 diabetes. Lancet 2017, 389, 2239-2251. [CrossRef]

5. Kim, T.N.; Park, M.S.; Yang, S.J.; Yoo, H.J.; Kang, H.J.; Song, W.; Seo, J.A.; Kim, S.G.; Kim, N.H.; Baik, S.H.; et al. Prevalence and determinant factors of sarcopenia in patients with type 2 diabetes: The Korean Sarcopenic Obesity Study (KSOS). Diabetes Care 2010, 33, 1497-1499. [CrossRef]

6. Leenders, M.; Verdijk, L.B.; van der Hoeven, L.; Adam, J.J.; van Kranenburg, J.; Nilwik, R.; van Loon, L.J. Patients with type 2 diabetes show a greater decline in muscle mass, muscle strength, and functional capacity with aging. J. Am. Med. Dir. Assoc. 2013, 14, 585-592. [CrossRef]

7. Umegaki, H. Sarcopenia and diabetes: Hyperglycemia is a risk factor for age-associated muscle mass and functional reduction. $J$ Diabetes Investig. 2015, 6, 623-624. [CrossRef]

8. Jang, H.C. Sarcopenia, Frailty, and Diabetes in Older Adults. Diabetes Metab. J. 2016, 40, 182-189. [CrossRef] [PubMed]

9. Sarodnik, C.; Bours, S.P.G.; Schaper, N.C.; van den Bergh, J.P.; van Geel, T. The risks of sarcopenia, falls and fractures in patients with type 2 diabetes mellitus. Maturitas 2018, 109, 70-77. [CrossRef] [PubMed]

10. Umegaki, H. Sarcopenia and frailty in older patients with diabetes mellitus. Geriatr. Gerontol. Int. 2016, 16, 293-299. [CrossRef] [PubMed]

11. Akpinar, T.S.; Tayfur, M.; Tufan, F.; Sahinkaya, T.; Kose, M.; Ozsenel, E.B.; Bahat Ozturk, G.; Saka, B.; Erten, N.; Yildiz, S.; et al. Uncomplicated diabetes does not accelerate age-related sarcopenia. Aging Male 2014, 17, 205-210. [CrossRef]

12. Mesinovic, J.; Zengin, A.; De Courten, B.; Ebeling, P.R.; Scott, D. Sarcopenia and type 2 diabetes mellitus: A bidirectional relationship. Diabetes Metab. Syndr. Obes. 2019, 12, 1057-1072. [CrossRef]

13. Trierweiler, H.; Kisielewicz, G.; Hoffmann Jonasson, T.; Rasmussen Petterle, R.; Aguiar Moreira, C.; Zeghbi Cochenski Borba, V. Sarcopenia: A chronic complication of type 2 diabetes mellitus. Diabetol. Metab. Syndr. 2018, 10, 25. [CrossRef] [PubMed]

14. Walston, J.D. Sarcopenia in older adults. Curr. Opin. Rheumatol. 2012, 24, 623-627. [CrossRef]

15. Arai, H.; Wakabayashi, H.; Yoshimura, Y.; Yamada, M.; Kim, H.; Harada, A. Chapter 4 Treatment of sarcopenia. Geriatr. Gerontol. Int. 2018, 18 (Suppl. 1), 28-44. [CrossRef]

16. Naseeb, M.A.; Volpe, S.L. Protein and exercise in the prevention of sarcopenia and aging. Nutr. Res. 2017, 40, 1-20. [CrossRef] [PubMed]

17. Paddon-Jones, D.; Short, K.R.; Campbell, W.W.; Volpi, E.; Wolfe, R.R. Role of dietary protein in the sarcopenia of aging. Am. J. Clin. Nutr. 2008, 87, 1562S-1566S. [CrossRef] [PubMed]

18. Krok-Schoen, J.L.; Archdeacon Price, A.; Luo, M.; Kelly, O.J.; Taylor, C.A. Low Dietary Protein Intakes and Associated Dietary Patterns and Functional Limitations in an Aging Population: A NHANES analysis. J. Nutr. Health Aging 2019, 23, 338-347. [CrossRef]

19. Campins, L.; Camps, M.; Riera, A.; Pleguezuelos, E.; Yebenes, J.C.; Serra-Prat, M. Oral Drugs Related with Muscle Wasting and Sarcopenia. A Review. Pharmacology 2017, 99, 1-8. [CrossRef] [PubMed]

20. Granic, A.; Sayer, A.A.; Robinson, S.M. Dietary Patterns, Skeletal Muscle Health, and Sarcopenia in Older Adults. Nutrients 2019, 11, 745. [CrossRef]

21. Johnson, C.L.; Dohrmann, S.M.; Burt, V.L.; Mohadjer, L.K. National Health and Nutrition Examination Survey: Sample design, 2011-2014. Stat. Vital Health Stat. 2014, 2, 1-33.

22. Centers for Disease Control and Prevention. National Health and Nutrition Examination Survey: NCHS Research Ethics Review Board (ERB) Approval. Available online: https://www.cdc.gov/nchs/nhanes/irba98.htm (accessed on 26 July 2021).

23. American Diabetes Association. 2. Classification and Diagnosis of Diabetes: Standards of Medical Care in Diabetes-2019. Diabetes Care 2019, 42, S13-S28. [CrossRef] [PubMed]

24. Centers for Disease Control and Prevention. National Health and Nutrition Examination Survey (NHANES) MEC In-Person Dietary Interviewers Procedures Manual. National Health and Nutrition Examination Survey, Ed.; 2016. Available online: https: //wwwn.cdc.gov/nchs/data/nhanes/2017-2018/manuals/2017_MEC_In-Person_Dietary_Interviewers_Manual.pdf (accessed on 27 July 2021).

25. Moshfegh, A.J.; Rhodes, D.G.; Baer, D.J.; Murayi, T.; Clemens, J.C.; Rumpler, W.V.; Paul, D.R.; Sebastian, R.S.; Kuczynski, K.J.; Ingwersen, L.A.; et al. The US Department of Agriculture Automated Multiple-Pass Method reduces bias in the collection of energy intakes. Am. J. Clin. Nutr. 2008, 88, 324-332. [CrossRef]

26. Rhodes, D.G.; Murayi, T.; Clemens, J.C.; Baer, D.J.; Sebastian, R.S.; Moshfegh, A.J. The USDA Automated Multiple-Pass Method accurately assesses population sodium intakes. Am. J. Clin. Nutr. 2013, 97, 958-964. [CrossRef] [PubMed]

27. Krebs-Smith, S.M.; Pannucci, T.E.; Subar, A.F.; Kirkpatrick, S.I.; Lerman, J.L.; Tooze, J.A.; Wilson, M.M.; Reedy, J. Update of the Healthy Eating Index: HEI-2015. J. Acad. Nutr. Diet 2018, 118, 1591-1602. [CrossRef]

28. Institute of Medicine. Dietary Reference Intakes for Energy, Carbohydrate, Fiber, Fat, Fatty Acids, Cholesterol, Protein, and Amino Acids; The National Academies Press: Washington, DC, USA, 2005; 1358p. [CrossRef] 
29. Nelson, K.M.; Reiber, G.; Boyko, E.J.; NHANES, III. Diet and exercise among adults with type 2 diabetes: Findings from the third national health and nutrition examination survey (NHANES III). Diabetes Care 2002, 25, 1722-1728. [CrossRef]

30. Hiza, H.A.; Casavale, K.O.; Guenther, P.M.; Davis, C.A. Diet quality of Americans differs by age, sex, race/ethnicity, income, and education level. J. Acad. Nutr. Diet 2013, 113, 297-306. [CrossRef]

31. Rehm, C.D.; Penalvo, J.L.; Afshin, A.; Mozaffarian, D. Dietary Intake Among US Adults, 1999-2012. JAMA 2016, 315, 2542-2553. [CrossRef] [PubMed]

32. Wilson, M.M.; Reedy, J.; Krebs-Smith, S.M. American Diet Quality: Where It Is, Where It Is Heading, and What It Could Be. J. Acad. Nutr. Diet. 2016, 116, 302-310. [CrossRef]

33. Bowman, S.A.; Lino, M.; Gerrior, S.A.; Basiotis, P.P. The Healthy Eating Index: 1994-96; US Department of Agriculture, Center for Nutrition Policy and Promotion: Washington, DC, USA, 1998. [CrossRef]

34. American Diabetes Association. 3. Prevention or Delay of Type 2 Diabetes: Standards of Medical Care in Diabetes-2019. Diabetes Care 2019, 42, S29-S33. [CrossRef] [PubMed]

35. American Diabetes Association. 5. Lifestyle Management: Standards of Medical Care in Diabetes-2019. Diabetes Care 2019, 42, S46-S60. [CrossRef] [PubMed]

36. Hallberg, S.J.; McKenzie, A.L.; Williams, P.T.; Bhanpuri, N.H.; Peters, A.L.; Campbell, W.W.; Hazbun, T.L.; Volk, B.M.; McCarter, J.P.; Phinney, S.D.; et al. Effectiveness and Safety of a Novel Care Model for the Management of Type 2 Diabetes at 1 Year: An Open-Label, Non-Randomized, Controlled Study. Diabetes Ther. 2018, 9, 583-612. [CrossRef] [PubMed]

37. Sainsbury, E.; Kizirian, N.V.; Partridge, S.R.; Gill, T.; Colagiuri, S.; Gibson, A.A. Effect of dietary carbohydrate restriction on glycemic control in adults with diabetes: A systematic review and meta-analysis. Diabetes Res. Clin. Pr. 2018, 139, $239-252$. [CrossRef] [PubMed]

38. Saslow, L.R.; Daubenmier, J.J.; Moskowitz, J.T.; Kim, S.; Murphy, E.J.; Phinney, S.D.; Ploutz-Snyder, R.; Goldman, V.; Cox, R.M.; Mason, A.E.; et al. Twelve-month outcomes of a randomized trial of a moderate-carbohydrate versus very low-carbohydrate diet in overweight adults with type 2 diabetes mellitus or prediabetes. Nutr. Diabetes 2017, 7, 304. [CrossRef] [PubMed]

39. Estruch, R.; Ros, E.; Salas-Salvado, J.; Covas, M.I.; Corella, D.; Aros, F.; Gomez-Gracia, E.; Ruiz-Gutierrez, V.; Fiol, M.; Lapetra, J.; et al. Primary Prevention of Cardiovascular Disease with a Mediterranean Diet. Supplemented with Extra-Virgin Olive Oil or Nuts. N. Engl. J. Med. 2018, 378, e34. [CrossRef]

40. Wang, D.D.; Li, Y.; Chiuve, S.E.; Stampfer, M.J.; Manson, J.E.; Rimm, E.B.; Willett, W.C.; Hu, F.B. Association of Specific Dietary Fats With Total and Cause-Specific Mortality. JAMA Intern. Med. 2016, 176, 1134-1145. [CrossRef] [PubMed]

41. Rietman, A.; Schwarz, J.; Tome, D.; Kok, F.J.; Mensink, M. High dietary protein intake, reducing or eliciting insulin resistance? Eur. J. Clin. Nutr. 2014, 68, 973-979. [CrossRef] [PubMed]

42. Ma, J.; Stevens, J.E.; Cukier, K.; Maddox, A.F.; Wishart, J.M.; Jones, K.L.; Clifton, P.M.; Horowitz, M.; Rayner, C.K. Effects of a protein preload on gastric emptying, glycemia, and gut hormones after a carbohydrate meal in diet-controlled type 2 diabetes. Diabetes Care 2009, 32, 1600-1602. [CrossRef] [PubMed]

43. Veldhorst, M.; Smeets, A.; Soenen, S.; Hochstenbach-Waelen, A.; Hursel, R.; Diepvens, K.; Lejeune, M.; Luscombe-Marsh, N.; Westerterp-Plantenga, M. Protein-induced satiety: Effects and mechanisms of different proteins. Physiol. Behav. 2008, 94, 300-307. [CrossRef]

44. O'Keefe, J.H.; Bell, D.S. Postprandial hyperglycemia/hyperlipidemia (postprandial dysmetabolism) is a cardiovascular risk factor. Am. J. Cardiol. 2007, 100, 899-904. [CrossRef]

45. Ward, R.E.; Orkaby, A.R.; Chen, J.; Hshieh, T.T.; Driver, J.A.; Gaziano, J.M.; Djousse, L. Association between Diet Quality and Frailty Prevalence in the Physicians' Health Study. J. Am. Geriatr. Soc. 2020, 68, 770-776. [CrossRef]

46. Bray, G.A.; Smith, S.R.; de Jonge, L.; Xie, H.; Rood, J.; Martin, C.K.; Most, M.; Brock, C.; Mancuso, S.; Redman, L.M. Effect of dietary protein content on weight gain, energy expenditure, and body composition during overeating: A randomized controlled trial. JAMA 2012, 307, 47-55. [CrossRef]

47. Kim, H.; Hirano, H.; Edahiro, A.; Ohara, Y.; Watanabe, Y.; Kojima, N.; Kim, M.; Hosoi, E.; Yoshida, Y.; Yoshida, H.; et al. Sarcopenia: Prevalence and associated factors based on different suggested definitions in community-dwelling older adults. Geriatr. Gerontol. Int. 2016, 16 (Suppl. 1), 110-122. [CrossRef]

48. Hida, T.; Shimokata, H.; Sakai, Y.; Ito, S.; Matsui, Y.; Takemura, M.; Kasai, T.; Ishiguro, N.; Harada, A. Sarcopenia and sarcopenic leg as potential risk factors for acute osteoporotic vertebral fracture among older women. Eur. Spine. J. 2016, 25, 3424-3431. [CrossRef]

49. Sanada, K.; Miyachi, M.; Tanimoto, M.; Yamamoto, K.; Murakami, H.; Okumura, S.; Gando, Y.; Suzuki, K.; Tabata, I.; Higuchi, M. A cross-sectional study of sarcopenia in Japanese men and women: Reference values and association with cardiovascular risk factors. Eur. J. Appl. Physiol. 2010, 110, 57-65. [CrossRef]

50. Lee, C.G.; Boyko, E.J.; Strotmeyer, E.S.; Lewis, C.E.; Cawthon, P.M.; Hoffman, A.R.; Everson-Rose, S.A.; Barrett-Connor, E.; Orwoll, E.S.; Osteoporotic Fractures in Men Study Research Group. Association between insulin resistance and lean mass loss and fat mass gain in older men without diabetes mellitus. J. Am. Geriatr. Soc. 2011, 59, 1217-1224. [CrossRef] [PubMed]

51. Costantini, S.; Conte, C. Bone health in diabetes and prediabetes. World J. Diabetes 2019, 10, 421-445. [CrossRef] [PubMed]

52. Berryman, C.E.; Lieberman, H.R.; Fulgoni, V.L., 3rd; Pasiakos, S.M. Protein intake trends and conformity with the Dietary Reference Intakes in the United States: Analysis of the National Health and Nutrition Examination Survey, 2001-2014. Am. J. Clin. Nutr. 2018, 108, 405-413. [CrossRef] [PubMed] 
53. Bauer, J.; Morley, J.E.; Schols, A.; Ferrucci, L.; Cruz-Jentoft, A.J.; Dent, E.; Baracos, V.E.; Crawford, J.A.; Doehner, W.; Heymsfield, S.B.; et al. Sarcopenia: A Time for Action. An. SCWD Position Paper. J. Cachexia Sarcopenia Muscle 2019, 10, 956-961. [CrossRef] [PubMed]

54. Bauer, J.; Biolo, G.; Cederholm, T.; Cesari, M.; Cruz-Jentoft, A.J.; Morley, J.E.; Phillips, S.; Sieber, C.; Stehle, P.; Teta, D.; et al. Evidence-based recommendations for optimal dietary protein intake in older people: A position paper from the PROT-AGE Study Group. J. Am. Med. Dir. Assoc. 2013, 14, 542-559. [CrossRef]

55. Rizzoli, R.; Stevenson, J.C.; Bauer, J.M.; van Loon, L.J.; Walrand, S.; Kanis, J.A.; Cooper, C.; Brandi, M.L.; Diez-Perez, A.; Re-ginster, J.Y.; et al. The role of dietary protein and vitamin D in maintaining musculoskeletal health in postmenopausal wom-en: A consensus statement from the European Society for Clinical and Economic Aspects of Osteoporosis and Osteoarthritis (ESCEO). Maturitas 2014, 79, 122-132. [CrossRef] [PubMed]

56. Deutz, N.E.; Bauer, J.M.; Barazzoni, R.; Biolo, G.; Boirie, Y.; Bosy-Westphal, A.; Cederholm, T.; Cruz-Jentoft, A.; Krznaric, Z.; Nair, K.S.; et al. Protein intake and exercise for optimal muscle function with aging: Recommendations from the ESPEN Expert Group. Clin. Nutr. 2014, 33, 929-936. [CrossRef]

57. Beasley, J.M.; Rillamas-Sun, E.; Tinker, L.F.; Wylie-Rosett, J.; Mossavar-Rahmani, Y.; Datta, M.; Caan, B.J.; LaCroix, A.Z. Die-tary Intakes of Women's Health Initiative Long Life Study Participants Falls Short of the Dietary Reference Intakes. J. Acad. Nutr. Diet 2020, 120, 1530-1537. [CrossRef] [PubMed]

58. Shan, Z.; Rehm, C.D.; Rogers, G.; Ruan, M.; Wang, D.D.; Hu, F.B.; Mozaffarian, D.; Zhang, F.F.; Bhupathiraju, S.N. Trends in Dietary Carbohydrate, Protein, and Fat Intake and Diet Quality Among US Adults, 1999-2016. JAMA 2019, 322, $1178-1187$. [CrossRef]

59. Azami, Y.; Funakoshi, M.; Matsumoto, H.; Ikota, A.; Ito, K.; Okimoto, H.; Shimizu, N.; Tsujimura, F.; Fukuda, H.; Miyagi, C.; et al. Long working hours and skipping breakfast concomitant with late evening meals are associated with suboptimal gly-cemic control among young male Japanese patients with type 2 diabetes. J. Diabetes Investig. 2019, 10, 73-83. [CrossRef] [PubMed]

60. Matia Martin, P.; Robles Agudo, F.; Lopez Medina, J.A.; Sanz Paris, A.; Tarazona Santabalbina, F.; Domenech Pascual, J.R.; Lopez Penabad, L.; Sanz Barriuso, R.; GluceNut Study, G. Effectiveness of an oral diabetes-specific supplement on nutritional status, metabolic control, quality or life, and functional status in elderly patients. A multicentre study. Clin. Nutr. 2019, 38, 1253-1261. [CrossRef] [PubMed] 